\title{
Alphaherpesvirus Vaccines
}

\author{
Clare Burn Aschner ${ }^{1}$ and Betsy C. Herold ${ }^{1,2 *}$ \\ ${ }^{1}$ Department of Microbiology-Immunology and 2Pediatrics, Albert Einstein \\ College of Medicine, Bronx, NY, USA \\ *betsy.herold@einsteinmed.org
}

DOI: https://doi.org/10.21775/cimb.041.469

\begin{abstract}
Prophylactic and therapeutic vaccines for the alphaherpesviruses including varicella zoster virus (VZV) and herpes simplex virus types 1 and 2 have been the focus of enormous preclinical and clinical research. A live viral vaccine for prevention of chickenpox and a subunit therapeutic vaccine to prevent zoster are highly successful. In contrast, progress towards the development of effective prophylactic or therapeutic vaccines against HSV-1 and HSV-2 has met with limited success. This review provides an overview of the successes and failures, the different types of immune responses elicited by various vaccine modalities, and the need to reconsider the preclinical models and immune correlates of protection against HSV.
\end{abstract}

\section{Background}

The Alphaherpesvirinae subfamily of the Herpesviridae are large, enveloped double-stranded DNA viruses that include several important human and animal pathogens. The majority of the world's population is infected with at least one or more of the three major human Alphaherpesvirinae: herpes simplex virus type 1 (HSV-1), HSV type 2 (HSV-2) and human herpesvirus 3, more commonly known as varicella zoster virus (VZV). This subfamily is 
differentiated from the beta and gammaherpesviruses by genetic and biological properties including a relatively short reproductive cycle, lytic infection in cell culture, and ability to universally establish latency primarily in sensory nerve ganglia. Viral latency is characterized by episodes of subclinical or, less commonly, clinical reactivation, which further fuel transmission and contribute to disease burden.

HSV-1 infects over 3.7 billion people worldwide and is the primary cause of oral HSV disease, as well as a leading cause of infectious corneal blindness and fatal sporadic encephalitis (Roberts et al. 2003). HSV-1 has also emerged as a leading cause of primary genital herpes in the United States and other developed nations (Roberts et al. 2003). HSV-2, which infects approximately 400 million people worldwide, primarily causes genital disease and is associated with an increased risk of HIV acquisition and transmission (Looker et al. 2015; Looker et al. 2017). There is significant geographic overlap when comparing the prevalence of HIV and HSV-2, and mathematical modeling indicates that a prophylactic HSV-2 vaccine would have a major impact on the HIV epidemic (Looker et al. 2017). HSV-2 is also associated with recurrent aseptic meningitis, known as Mollaret's syndrome (Whitley 2006). Perinatal transmission of both HSV-1 and HSV-2, the incidence of which is estimated to be approximately 1 in 3200 live births in the United States, is associated with substantial morbidity even with appropriate antiviral therapy (James and Kimberlin 2015).

VZV causes the common, but usually self-limited primary childhood exanthemous illness, chickenpox. Clinical reactivation of VZV results in shingles or zoster, is typically restricted to one or a few dermatomes, and is more common in older or immunocompromised individuals (Ljungman et al. 1986). Less commonly, VZV can cause ocular disease including keratitis, uveitis or zoster opthalmicus. The latter is linked to VZV reactivation within the trigeminal ganglion and may lead to blindness. VZV may also cause a vasculopathy, which is associated with stroke and other vascular complications. Viral genetic studies have identified five VZV clades; clades 1, 3 
and 5 are of European origin, clade 2 dominates in Asia, and clade 4 in Africa (Schmidt-Chanasit and Sauerbrei 2011). The enormous global health and economic burden of alphaherpesvirus infections has generated extensive vaccine development efforts over the past decades. However, while there has been great success in developing vaccines to prevent varicella and to reduce the risk of zoster, there is to date no effective vaccine for HSV-1 or HSV-2.

\section{Varicella zoster vaccines}

Live attenuated varicella vaccine

A live attenuated varicella vaccine (LAVV) was initially developed in Japan in 1974 with the goal of reducing disease burden in children with leukemia. The vaccine was attenuated by serially passaging a varicella strain isolated from a child whose last name was Oka (Oka strain) in guinea pig embryo cultures and then subsequently propagating the virus in human diploid cells (Takahashi et al. 1974). The vaccine strain (vOka) is attenuated primarily for replication in the skin but less so in T cells or trigeminal ganglia (Moffat et al. 1998). It also establishes latency, albeit less efficiently than primary infection (Moffat et al. 1998). Zoster attributable to reactivation of vOka occurs much less frequently ( $\sim 7$ fold less in children with leukemia) than reactivation of wild-type virus (Krause and Klinman 2000).

Although there were initial concerns about the safety of a live, attenuated viral vaccine, the extensive data in children with leukemia in remission (Hattori et al. 1976; Brunell et al. 1982) and subsequent studies in healthy children (Asano and Takahashi 1977; Weibel et al. 1985; White et al. 1991; White 1996) led to licensure of LAVV as a single-dose, universal vaccination of all healthy children 1-13 years of age and healthy adults in the United States in 1995 (Gershon 1980; White et al. 1991). However, numerous varicella outbreaks were reported among immunized school-aged children in the 1990s, which, combined with documentation of lower than initially anticipated seroconversion rates, led to the adoption in 2006 of a routine two-dose schedule with initial vaccination between 12-15 months and a booster at 4-6 years (Watson et al. 1995; Arvin and Gershon 2006). This revised schedule has been associated 
with a greater than $95 \%$ decline in primary varicella disease in healthy children and has provided herd immunity for immunocompromised children for whom a live viral vaccine is not indicated (Shapiro et al. 2011). There are two licensed vaccine formulations: VARIVAX ${ }^{\circledR}$, the single-antigen varicella vaccine, and ProQuad $^{\circledR}$, a combination measles, mumps, rubella, and varicella (MMRV) vaccine (Merck and Co).

VOka was sequenced years after initial licensure and is comprised of a mixture of VZV Oka genotypes and differs from wild-type strains by at least 224 single nucleotide polymorphisms (SNPs) (Argaw et al. 2000; Faga et al. 2001; Quinlivan and Breuer 2006). Precisely which ones are responsible for the attenuating phenotype is unknown, although studies indicate that mutations in ORF62, a critical viral transcription factor and homolog of HSV-1 ICP4, are important for attenuation (Kwak et al. 2017). The sequencing data allows for the differentiation of the vaccine strain from the wild-type virus circulating in the United States, since the majority of clade 2 VZV viruses have Bgl1 and Pst1 restriction sites as well as several SNPs that differentiate them from vOka (Quinlivan et al. 2012; Peters et al. 2012). This genetic information is used when differentiating vaccine-associated disease from breakthrough varicella caused by infections with the wild-type virus.

\section{Correlates of immune protection}

The precise correlates of immune protection against natural disease elicited by the VZV vaccine are not fully defined. Both cell-mediated and humoral immune responses are important, as evidenced by the observations that patients with impaired $T$ cell function are at risk for severe disease and that administration of high dose anti-VZV immune serum (zoster immune globulin) may prevent or modify disease manifestations (Arvin 2008). The gold standard for measuring antibody responses is the fluorescent antibody to membrane antigen assay (FAMA) against live VZV-infected cells. However, difficulties with assay reproducibility and automation have led to the development of alternatives including a glycoprotein (gp) based ELISA, which uses a lectin affinity purified preparation of viral glycoproteins from VZV-infected cells. FAMA VZV antibody 
titers $\geq 1: 4$ or gpELISA titers $\geq 5 \mathrm{gpELISA}$ units $/ \mathrm{ml}$ correlate with protection (Gershon et al. 1994). Limited studies demonstrate that natural infection and vaccination induce both neutralizing and antibody-dependent cell-mediated cytotoxicity (ADCC) immune responses, and FAMA titers correlate with both (Kamiya et al. 1982). Notably, in one study, ADCC responses were detected earlier than neutralizing responses, suggesting that $A D C C$ may be involved in the early stages of recovery from VZV disease (Ihara et al. 1994). Neutralizing antibodies target several viral glycoproteins, including $\mathrm{gE}, \mathrm{gB}$, and the $\mathrm{gH} / \mathrm{gL}$ heterodimer; the targets of $A D C C$ responses have not been delineated.

\section{Zoster vaccines}

The success of vaccination with the vOka strain against primary varicella suggested that the live, attenuated vaccine could also be used to boost immunity in older adults to prevent zoster. The rationale for this stemmed from clinical observations by Hope-Simpson, which suggested that exposure to exogenous (chickenpox in the community) and/or endogenous (reactivation) VZV stimulated memory T cell responses (Hope-Simpson 1965; Guzzetta et al. 2013). This notion was supported by the recognition that second episodes of zoster were uncommon. Building on these observations, a double-blind, placebo-controlled trial in heathy adults $\geq 60$ years of age was conducted to compare a single dose of high-potency (14x greater than primary LAVV dose) vOka compared to placebo (Oxman et al. 2008). This dose was selected based on cell-mediated immune responses. There were 38,546 healthy adults enrolled in the study who were randomized 1:1 to receive vaccine or placebo. There were 315 confirmed cases of zoster in vaccine recipients compared to 642 cases in placebo recipients; none of the zoster isolates were the vaccine strain. Based on these results, this high dose LAVV, marketed as Zostavax (Merck and Co) was licensed by the FDA in 2006 and recommended by the $\mathrm{CDC}$ for routine immunization of healthy adults aged $>50$ for the prevention of zoster and post-herpetic neuralgia.

More recently, Shingrix, a liposome-based subunit vaccine containing recombinant glycoprotein $\mathrm{E}(\mathrm{gE})$, combined with adjuvants to stimulate strong 
CD4+ T cell responses (AS01B, the Toll-like receptor agonist monophosphoryl lipid A combined with saponin QS21), was developed by GlaxoSmithKline and evaluated for prevention of zoster. $\mathrm{gE}$ is the most abundant glycoprotein on VZV-infected cells and is a target for neutralizing antibody responses. Two large Phase III placebo-controlled trials in healthy adults $>50$ years or $>70$ years using a 2-dose schedule of Shingrix demonstrated $97 \%$ protection against zoster compared to the $51 \%$ efficacy observed in response to Zostavax. Shingrix was approved by the FDA at the end of 2017 (Lal et al. 2015; Cunningham et al. 2016).

The specific correlates of immune protection for these vaccines are not yet fully defined. Both Zostavax and Shingrix boost cell-mediated immune responses but differ with respect to antigenic targets (Sei et al. 2015). T cell responses to Zostavax target IE63, IE62, gB and ORF9 more frequently than $\mathrm{gE}$, whereas Shingrix, as expected, elicits gE-specific responses (Weinberg, Kroehl, et al. 2018). However, strong gE-specific CD4+ T cell responses are observed only after the second dose of Shingrix, suggesting that the majority of this response may be dependent on stimulation of otherwise naïve cells (Weinberg, Kroehl, et al. 2018; Weinberg, Popmihajlov, et al. 2018). In addition to the T cell responses, a 4-fold or greater rise in gE-specific antibody responses was observed in over $97 \%$ of Shingrix recipients.

In addition to greater immunogenicity and efficacy, an important advantage of Shingrix is that, as a subunit vaccine, it may be safely administered to immunocompromised hosts. Studies are ongoing in adult solid-organ transplant recipients (Stadtmauer et al. 2014; Winston et al. 2018) and in HIVinfected patients (Berkowitz et al. 2014). Additional questions that require future studies include the durability of the response to Shringrix, and whether patients who received Zostavax should also receive a booster dose of Shingrix. Whether there is any role for this subunit vaccine in preventing or boosting immunity to prevent primary chickenpox will also require future investigations. 


\section{Herpes simplex virus vaccines}

\section{Obstacles to HSV prevention}

In contrast to the successes with VZV, an effective prophylactic or therapeutic vaccine for HSV has remained elusive. A live viral vaccine for varicella was developed in response to a specific population, children with leukemia, in whom the morbidity and mortality drove vaccine development. Only after the vaccine was shown to be safe and effective in this high-risk group, was it evaluated and approved for healthy children, providing herd immunity and thus further protection for high-risk populations. Although HSV also causes devastating disease in the subset of patients who develop encephalitis, overwhelming hepatic failure, dissemination to other organs, and recurrent corneal disease with blindness, the drive for a vaccine has been driven more by the morbidity and social stigma associated with HSV as a sexually transmitted infection and its link to HIV. Until very recently, the majority of vaccine efforts have focused on subunit protein strategies and neutralizing antibody responses, and this focus may have contributed to the lack of success.

One of the difficulties in designing a vaccine for any herpesvirus is the ability of all of these viruses (except HHV-8) to uniformly establish latency. However, subclinical and clinical reactivations are more common with HSV than VZV, reflecting a greater ability for the immune system to prevent or control latent VZV (Kronenberg et al. 2005; Papaevangelou et al. 2013). The term "leaky latency" has been proposed to better describe latent HSV (Wald et al. 1995; Wald et al. 2000; Mark et al. 2008). The natural immune response to HSV limits the number and severity of clinical recurrences and provides partial protection against heterologous (opposite serotype) challenge, but does not prevent viral reactivation. Thus, effective vaccines must elicit a more potent and/or different type of immune response compared to natural infection if the goals are to prevent the establishment of latency (prophylaxis) and/or provide greater protection against viral reactivation and transmission (therapeutic). Whether it is possible to safely eliminate the latent viral reservoir in seropositive individuals, a goal for HIV cure, is unknown. In addition, because 
of the high rate of HSV-1 seropositivity at a very young age, a vaccine ideally should be immunogenic in the setting of preexisting HSV-1 immunity (Roberts et al. 2003).

HSV-1 and HSV-2 have evolved a myriad of immune evasion strategies, many of which are unique to HSV and need to be considered in vaccine development. The ability of the virus to evade innate, humoral, and $T$ cell immunity may contribute to the greater difficulty in developing an effective HSV vaccine. Examples of these immune evasion strategies are summarized below. Both HSV-1 and HSV-2 encode several proteins (e.g. ICPO and ICP34.5) that inhibit interferon production and/or subsequent signal transduction to evade this major innate immune pathway (Chew et al. 2009). HSV also evades antibody responses through multiple mechanisms. First, the virus spreads directly from infected to neighboring uninfected cells across bridges, thus evading neutralizing antibodies (Sattentau 2008). Second, HSV glycoproteins $\mathrm{E}$ and $\mathrm{I}(\mathrm{gE} / \mathrm{gl})$ act as an $\mathrm{Fc}$ receptor $(\mathrm{FcR})$ analog, thereby shielding antibodies from engaging FcRs, which are required for non-neutralizing antibody dependent cell killing (Dubin et al. 1991; McNearney 1987). gE-gl may also promote clearance of viral antigen-Ab complexes and immune evasion through a process termed antibody bipolar bridging. The Fab fragment of IgG binds viral protein (e.g. gD) and the Fc fragment binds $\mathrm{gE}$-gl, leading to endocytosis of the complex (Ndjamen et al. 2014). Third, HSV glycoprotein C $(\mathrm{gC})$ interferes with the $\mathrm{C} 3$ complement cascade inhibiting complementmediated lysis of virus and infected cells (Gerber et al. 1995; Friedman et al. 1984; Fries et al. 1986). Another potential immune evasion strategy is the binding of $\mathrm{gD}$ to herpesvirus entry mediator (HVEM) on immune cells, which competes with binding of its natural ligands (Spear 2004). HVEM binding to LIGHT (TNFSF14) (Mauri et al. 1998; Kwon et al. 1997) provides a stimulatory signal (Harrop, Reddy, et al. 1998; Harrop, McDonnell, et al. 1998; Tamada et al. 2000; Shi 2002), whereas binding to B and T lymphocyte attenuator (BTLA) (Šedý et al. 2004; Cheung et al. 2009) provides an inhibitory signal to T cells and $\mathrm{gD}$ may interfere with these responses to modulate immune responses (Sarrias et al. 2000; Carfi et al. 2001; Connolly et al. 2002; Carfi et al. 2002; 
Connolly et al. 2003; Compaan et al. 2005; Stiles et al. 2010; T. L. Murphy and K. M. Murphy 2010). Moreover, HSV-2 gD induces the degradation of CD112/ nectin-2, a ligand for the NK-activating receptor DNAX accessory molecule 1 (DNAM-1). This impairs binding of DNAM-1 to the cell surface, thereby suppressing NK-mediated killing of HSV-2 infected cells (Grauwet et al. 2014). Finally, HSV also interferes with T cell responses. HSV ICP47 binds the human transporter associated with antigen presentation (TAP) and blocks the binding of antigenic peptides thus interfering with the major histocompatibility complex (MHC) class I antigen presentation pathway (Hill et al. 1995; Früh et al. 1995; Tomazin et al. 1996; Ahn et al. 1996).

VZV has also developed several immune evasion strategies, but these are more limited. For example, VZV interferes with interferon $\alpha$ and $\beta$ production by epithelial cells by sequestering NF-KB proteins in the cytoplasm, but neighboring uninfected cells overcome this evasion strategy (Jones and Arvin 2006). The strongest immune evasion by VZV is linked to the $T$ cell response. VZV down regulates MHC class I (Abendroth et al. 2001) and inhibits the upregulation of interferon- $\gamma$-induced $\mathrm{MHC}$ class II expression (Abendroth et al. 2000). However, shielding of antibodies through FcR mimicry and interference with complement pathway have not been described for VZV.

\section{HSV prophylactic subunit vaccine clinical trials}

Two subunit vaccines progressed through Phase 3 clinical efficacy trials as prophylactic vaccines with limited success (Table 1). Both were predicated on the notion that high titer neutralizing Abs targeting $\mathrm{gD}$ and/or $\mathrm{gB}$, which are the primary targets of neutralizing antibody responses during natural infection (in contrast to gE for VZV) would prove protective and were supported by studies in murine and guinea pig models. However, neither the recombinant $\mathrm{gB} / \mathrm{gD} /$ MF59 vaccine, which included a squalene-based adjuvant [Chiron], nor the recombinant gD-2/AS04 (Simplirix ${ }^{T M}$ ) vaccine, which used an alummonophosphoryl lipid A-based adjuvant [GSK], achieved their endpoints. 


\begin{tabular}{|c|c|c|c|c|}
\hline Name & Platform & Antigens & $\begin{array}{l}\text { Immune } \\
\text { Response }\end{array}$ & Clinical Results \\
\hline $\begin{array}{l}\text { gB/gD/MF59 } \\
\text { (Chiron) }\end{array}$ & $\begin{array}{l}\text { Subunit } \\
\text { MF59 adjuvant }\end{array}$ & $\mathrm{gD}$ and $\mathrm{gB}$ & Neutralizing Abs & $\begin{array}{l}\text { Phase } 3 \text { Prophylaxis } \\
9 \%(95 \% \mathrm{Cl}:-29 \% \text {, } \\
36 \%)\end{array}$ \\
\hline $\begin{array}{l}\text { gD/AS04 } \\
\text { (GSK) }\end{array}$ & $\begin{array}{l}\text { Subunit } \\
\text { AS04 adjuvant }\end{array}$ & $\mathrm{gD}$ & $\begin{array}{l}\text { Neutralizing Abs } \\
\text { CD4+ T cells }\end{array}$ & $\begin{array}{l}\text { Phase } 3 \text { Prophylaxis } \\
20 \% \text { (95\% Cl: }-29 \% \text {, } \\
50 \%)\end{array}$ \\
\hline $\begin{array}{l}\text { gH-null } \\
\text { (Cantab } \\
\text { Pharmaceuticals) }\end{array}$ & Single-cycle live & Multiple & Neutralizing Abs & $\begin{array}{l}\text { Phase } 3 \text { therapeutic } \\
\text { No difference in } \\
\text { recurrences or } \\
\text { shedding }\end{array}$ \\
\hline $\begin{array}{l}\text { HSV529 } \\
\text { (Sanofi-Pasteur) }\end{array}$ & $\begin{array}{l}\text { Replication- } \\
\text { defective }\end{array}$ & Multiple & $\begin{array}{l}\text { Neutralizing Abs } \\
\text { CD4, CD8 T cells }\end{array}$ & $\begin{array}{l}\text { Phase } 1 \\
\text { Safe but } \\
\text { immunogenic in } \\
\text { doubly- } \\
\text { seronegatives only }\end{array}$ \\
\hline $\begin{array}{l}\text { Gen-003 } \\
\text { (Genocea) }\end{array}$ & $\begin{array}{l}\text { Subunit } \\
\text { Saponin adjuvant }\end{array}$ & gD, ICP4 & $\begin{array}{l}\text { Neutralizing Abs } \\
\text { Cytolytic T cells }\end{array}$ & $\begin{array}{l}\text { Phase } 2 \text { therapeutic } \\
\text { Dose variable } \\
\text { decrease shedding }\end{array}$ \\
\hline $\begin{array}{l}\text { HerpV } \\
\text { (Agenus) }\end{array}$ & $\begin{array}{l}\text { Heat shock protein } \\
\text { 70-HSV peptides } \\
\text { QS-21 adjuvant }\end{array}$ & $\begin{array}{l}32 \text { HSV peptides } \\
\text { (gD, additional } \\
\text { envelope, tegument, } \\
\text { and other) }\end{array}$ & Cytotoxic $T$ cells & $\begin{array}{l}\text { Phase } 2 \text { therapeutic } \\
17 \% \text { reduction in } \\
\text { shedding frequency }\end{array}$ \\
\hline $\begin{array}{l}\text { Vaxfectin } \\
\text { (Vical) }\end{array}$ & $\begin{array}{l}\text { DNA } \\
\text { Vaxfectin adjuvant }\end{array}$ & gD, UL46/47 & Neutralizing Abs & $\begin{array}{l}\text { Phase } 1 / 2 \\
\text { therapeutic } \\
\text { Failed to reduce } \\
\text { shedding }\end{array}$ \\
\hline $\begin{array}{l}\text { COR-1 } \\
\text { (Admedus) }\end{array}$ & $\begin{array}{l}\text { Codon optimized } \\
\text { DNA }\end{array}$ & $\begin{array}{l}\text { Codon optimized } \\
\text { gD2 and ubiquitin- } \\
\text { fused truncated gD2 } \\
\text { to target the antigen } \\
\text { to the proteasome }\end{array}$ & $\begin{array}{l}\text { gD-specific Abs } \\
\text { Cytotoxic T cells }\end{array}$ & $\begin{array}{l}\text { Phase } 2 \text { therapeutic } \\
\text { No difference in } \\
\text { recurrences }\end{array}$ \\
\hline $\begin{array}{l}\triangle \mathrm{NLS} \\
\text { (Rational Vaccines) }\end{array}$ & $\begin{array}{l}\text { Deleted in ICPO } \\
\text { Replication } \\
\text { competent } \\
\text { Attenuated for } \\
\text { latency }\end{array}$ & Multiple targets & $\begin{array}{l}\text { Neutralizing Abs } \\
\text { gD-specific Abs }\end{array}$ & $\begin{array}{l}\text { Phase } 1 \text { non-FDA } \\
\text { approved } \\
\text { therapeutic study } \\
\text { Self-reported } \\
\text { reduction in } \\
\text { recurrences }\end{array}$ \\
\hline
\end{tabular}

The gB/gD/MF59 vaccine was evaluated in two randomized, double-blind, placebo-controlled multicenter trials. One trial enrolled 531 HSV-2seronegative partners of HSV-2-seropositive people, and the other enrolled 1862 persons attending sexually transmitted disease clinics. The vaccine 
induced high levels of neutralizing antibodies, but the overall vaccine efficacy was $9 \%$ (95\% confidence interval, $29 \%$ to $36 \%$ ) (Corey et al. 1999). The authors concluded that prevention will likely require more than high titer neutralizing antibodies. In subsequent studies, they found that the vaccine did not elicit ADCC antibodies and hypothesized that low ADCC responses may be associated with poor vaccine efficacy (Kohl et al. 2000).

Others speculated that the reason for the vaccine failure might be attributable to the need for higher neutralizing antibody titers and/or more potent $T$ cell responses and focused their efforts on combining gD with different adjuvants. Thus, the gD-2/AS04 vaccine, composed of gD-2 with monophosphoryl lipid A (MPL) and aluminum hydroxide (Alum), was evaluated in three different Phase 3 clinical trials. The first two studies were conducted in serodiscordant couples. In one, 847 doubly seronegative participants ( 268 women) were enrolled and in the other, $1867 \mathrm{HSV}-1$ seropositive (710 women) were enrolled. Combining the data from both studies showed that that the vaccine was $\sim 70 \%$ protective in doubly-seronegative women, but was not protective in HSV-1 seropositive women or in men regardless of their serostatus (Stanberry et al. 2002). The reasons for this sex discrepancy in protection in the HSV-1 seronegative participants were not understood.

The subpopulation results supported a third clinical field trial, which enrolled 8323 doubly-seronegative women 18 to 30 years of age with a primary endpoint of genital herpes disease caused by either serotype. The overall vaccine efficacy was only $20 \%$ (95\% confidence interval [Cl], $29 \%$ to $50 \%$ ) against genital herpes disease; however, modest efficacy against HSV-1 genital disease $(58 \% ; 95 \% \mathrm{Cl}, 12 \%$ to $80 \%$ ) was observed (Belshe et al. 2012). In a subsequent analysis of sera from 30 participants, the neutralizing antibody titers against HSV-1 were 3.5-fold higher than the titers against HSV-2, possibly reflecting serotype differences in the ability of the immune evading glycoproteins, $\mathrm{gE}$ and $\mathrm{gC}$, to interfere with the neutralization activity of the gD-specific neutralizing antibodies (Awasthi, Belshe, et al. 2014). Overall, these disappointing clinical trial outcomes with adjuvanted gD subunit vaccines 
raised questions about the reliance on neutralizing antibodies as a sole correlate of immune protection and challenged the traditional preclinical models that were conducted with intravaginal challenges in female mice or guinea pigs with laboratory-adapted HSV-2 isolates at doses that typically do not exceed an LD90 (dose that causes lethal disease in $90 \%$ of control animals).

\section{"Next generation" prophylactic subunit vaccine candidates}

Building on the observation that HSV $\mathrm{gE}$ and $\mathrm{gC}$ are immune evasion molecules that might shield against neutralizing antibodies, Friedman and colleagues developed a trivalent subunit vaccine (THV) comprised of gD, gC and gE (Table 2) (Awasthi, Huang, et al. 2014). Preclinical data using the standard murine or guinea pig models suggest that the trivalent vaccine is more potent than recombinant $\mathrm{gD}$ alone. The THV protected $100 \%$ of mice following intravaginal challenge with a $3 \times L_{50}$ dose of the laboratory-adapted strain of HSV-2, MS, and $97 \%$ of mice were protected from the establishment of latent infection in the dorsal root ganglia (DRG). In a female guinea pig vaginal challenge model, the THV and recombinant gD-2 vaccines were both highly effective in preventing genital lesions (Awasthi, Hook, Shaw, Pahar, et

\begin{tabular}{|c|c|c|c|c|}
\hline Candidate & Platform & $\begin{array}{l}\text { Antigenic } \\
\text { Targets }\end{array}$ & $\begin{array}{l}\text { Immune } \\
\text { Response }\end{array}$ & Results in animal models \\
\hline THV & Trivalent subunit & $\begin{array}{l}\mathrm{gD}, \mathrm{gC} \\
\mathrm{gE}\end{array}$ & Neutralizing Abs & $\begin{array}{l}\text { Prophylactic in mice and guinea pigs } \\
\text { Decreased shedding in guinea pigs }\end{array}$ \\
\hline$\Delta \mathrm{gD}-2$ & $\begin{array}{l}\text { gD null } \\
\text { Single cycle }\end{array}$ & $\begin{array}{l}\text { Multiple } \\
\text { targets } \\
\text { excluding } \\
\text { gD }\end{array}$ & $\begin{array}{l}\text { Fc } \gamma \text { R-activating } \\
\text { Abs } \\
\text { CD4, CD8 } \\
\text { responses } \\
\text { Passive protection }\end{array}$ & $\begin{array}{l}100 \% \text { protection against HSV-1 and } \\
\text { HSV- } 2 \text { clinical isolates in male and } \\
\text { female mice with multiple challenge } \\
\text { routes; } \\
\text { Prevents establishment of latency } \\
\text { Passive protection }\end{array}$ \\
\hline gD27 & $\begin{array}{l}\text { gD-nectin binding } \\
\text { impaired; Live } \\
\text { attenuated }\end{array}$ & Multiple & Neutralizing Abs & $\begin{array}{l}\text { Improved protection compared to gD-2 } \\
\text { subunit }\end{array}$ \\
\hline VC2 & $\begin{array}{l}\text { Deleted in gK and } \\
\text { UL20 } \\
\text { Defective in } \\
\text { establishing latency; } \\
\text { replication } \\
\text { competent }\end{array}$ & Multiple & $\begin{array}{l}\text { Neutralizing Abs } \\
\text { T cell memory (gB, } \\
\mathrm{gD}) \\
\mathrm{T}_{\mathrm{FH}} \text { and Th17 } \\
\text { responses }\end{array}$ & $\begin{array}{l}100 \% \text { protection in mice intravaginally } \\
\text { challenged with HSV-1(McKrae) or } \\
\text { HSV-2(G) } \\
\text { Prevents latency }\end{array}$ \\
\hline
\end{tabular}


al. 2017). Shedding of replication-competent virus (i.e. virus capable of infecting cells in a co-culture model) occurred on fewer days in the THV compared to gD-2/AS04 immunized animals, although there was no difference between the two vaccines in HSV DNA shedding, and the gD-specific serum antibody and neutralization titers with and without complement were similar (Awasthi, Hook, Shaw and Friedman 2017). Challenges with higher doses, clinical isolates, or in male animals (skin challenge) have not yet been reported. More recently, the group compared the THV vaccine, a protein-based vaccine, to a nucleoside-modified mRNA vaccine containing sequences for the same 3 viral proteins and formulated in lipid nanoparticles. The trivalent mRNA vaccine was superior to the THV protein vaccine and elicited higher titer ELISA IgG antibodies, neutralizing gD-specific antibodies and $\mathrm{CD}^{+} \mathrm{T}$ cell responses and was associated with decreased viral shedding following subclinical infections in mice and guinea pigs (Awasthi et al. 2019).

\section{Live attenuated or single-cycle HSV prophylactic vaccine candidates}

In contrast to subunit vaccines, live virus vaccines are likely to elicit polyfunctional immune responses targeting a greater breadth of antigens. In addition to the success of the live attenuated varicella vaccine, live virus vaccines have also had success against animal alphaherpesviruses. For example, a herpes turkey virus (HVT) vaccine has been used for years to immunize against the related Marek's Disease Virus (MDV) that causes an economically important neoplastic disease of chickens (Okazaki et al. 1970). Unfortunately, MDV has evolved to overcome the protection from the HVT vaccine, which has resulted in the need to modify the HVT strain to address the new outbreaks (Schat and Baranowski 2007). Live attenuated virus vaccines carrying deletions in specific viral proteins have also been used to protect against pseudorabies virus (PrV), the causative agent of Aujeszky's disease, another agriculturally and economically important infection that results in losses of swine populations (Bartha 1961). As with the vaccine for Marek's Disease, the PrV vaccines have to be modified to address changes in the circulating strains of PrV (Freuling et al. 2017). 
Candidates that have been evaluated in clinical trials

The expansion of molecular technologies has facilitated the engineering of live virus vaccine candidates with specific deletions in gene(s) of known function. This defined approach has replaced the strategy of attenuation by serial passage in culture, which was used to develop the varicella vaccine. The first such HSV vaccine candidate to be evaluated in clinical trials lacked the gene for glycoprotein $\mathrm{H}(\mathrm{gH})$ (Table 1) (McLean et al. 1994). $\mathrm{gH}$ (along with gD, gB, and $\mathrm{gL}$ ) is required for viral entry and cell-to-cell spread. Thus, the $\mathrm{gH}$-null virus, propagated in $\mathrm{gH}$-expressing complementing cells, is restricted to a single infectious cycle. The vaccine protected female guinea pigs from primary genital HSV-2, reduced the number of viral recurrences in the model, and elicited high serum neutralizing antibody responses (Boursnell et al. 1997). Based on these preclinical studies, this candidate was advanced into the clinic and evaluated as a therapeutic vaccine in volunteers with six or more annual genital herpes recurrences. The vaccine was safe, but there were no significant differences in the mean number of recurrences, time to healing, or days with viral shedding relative to placebo (de Bruyn et al. 2006). Specific immune responses to the vaccine, be they boosting of total, neutralizing, or other functional HSV-specific antibody or T cell responses, were not reported in the clinical trial. However, the lack of protection suggested that the preclinical models were not predictive of human clinical outcomes. The vaccine was not further pursued, and was never tested as a prophylactic.

Subsequently, several different replication-defective or single-cycle viruses have been engineered as candidate prophylactic vaccines. The first of these to enter clinical trial was an HSV-2 virus lacking the genes for UL5 (helicaseprimase) and UL29 (DNA binding protein) and designated dl5-29 or HSV529 (Da Costa et al. 2000; Da Costa et al. 2001). The virus was grown on complementing V295 cells, which stably express the HSV-2 UL5 and UL29 genes. The salient findings in the preclinical studies were that the vaccine was safe, generated high titer neutralizing antibody and CD4 and CD8 T cell responses, and protected against acute or recurrent genital HSV-2 disease in naïve female mice as well as naïve or HSV-1 seropositive female guinea pigs 
using vaginal challenge models (Hoshino et al. 2008). It reduced, but did not completely prevent the establishment of latency (Hoshino et al. 2004; Hoshino et al. 2009; Bernard et al. 2015). Notably, efficacy was reduced if mice were challenged with a clinical African HSV-2 isolate, SD90, suggesting that there may be differences in protective epitopes among clinical strains and highlighting the need for preclinical testing against a wide array of isolates (Dudek et al. 2011). HSV529 was recently evaluated in a Phase 1 study (Table 1). The vaccine was safe and elicited neutralizing and gD-specific antibody responses in doubly seronegative participants. However, in contrast to the studies in guinea pigs, the vaccine did not boost neutralizing antibody responses in HSV-1 or HSV-2 seropositive participants (Dropulic et al. 2017; Dropulic et al. 2019). Efforts to increase the immunogenicity of this vaccine are currently being evaluated. One such approach is to replace HSV-2 UL41, which encodes for the virion host shutoff (vhs) function, with the heterologous gene from HSV-1. The rationale for this intertypic recombination is that vhs-1 is 40-fold less active than vhs-2, and thus, that HSV-2 encoding vhs-1 might elicit a stronger immune response (Reszka et al. 2010).

\section{Candidates in preclinical development}

A completely different candidate live single-cycle vaccine in preclinical development is an HSV-2 virus lacking the $\mathrm{gD}$ gene $(\Delta \mathrm{gD}-2)$ (Table 2$)$. This candidate vaccine, which is grown on HSV-1 gD-expressing complementing cells, generates high titer antibodies and $T$ cell responses that recognize an array of HSV antigens exclusive of $\mathrm{gD}$. The preclinical model testing was expanded to include challenges with multiple clinical isolates of both HSV-1 and HSV-2, male and female mice, and several different routes of infection including intravaginal, skin, intraocular and intranasal (Burn et al. 2017; Ramsey et al. 2020; Burn Aschner, Knipe, et al. 2020). Most other vaccine candidates were tested using laboratory-adapted isolates of HSV-2 in vaginally challenged female animals. Results of the studies with $\triangle \mathrm{gD}-2$ demonstrated complete protection against disease and latency following challenge with all clinical isolates tested to date, including the African clinical isolate SD90 (Petro et al. 2015; Petro et al. 2016; Burn et al. 2017). No latent virus was detected in 
dorsal root ganglia in vaccinated mice by quantitative PCR or ex vivo cultures, further distinguishing this candidate vaccine from the subunit vaccines and from HSV529. The vaccine was equally protective in female and male mice following challenge with doses as high as 100x LD90 (Burn et al. 2017; Burn Aschner, Knipe, et al. 2020). Passive transfer studies demonstrated that antibodies alone were sufficient to mediate complete protection. Notably, the antibodies were weakly neutralizing, but activated the Fcy receptor IV (FcyRIV) to induce ADCC and antibody dependent cell mediated phagocytosis (ADCP) (Petro et al. 2015; Petro et al. 2016; Burn et al. 2017). Protection was lost in mice that did not express FcyRs and reduced in mice that did not express the Fc neonatal receptor.

In a direct comparison with an adjuvanted (alum and MPL) gD-2 subunit vaccine, $\Delta \mathrm{gD}-2$ provided significantly greater protection following high-dose skin challenges with clinical isolates of HSV-1 (strain $\mathrm{B}^{3} \mathrm{x}$ 1.1) and HSV-2 (strain SD90), a more robust total HSV-specific antibody response, and, in contrast to the gD-2 subunit vaccine, complete protection against the establishment of latency (Burn et al. 2017). While the gD-2 subunit vaccine elicited a predominantly lgG1 response, $\triangle \mathrm{gD}-2$ induced a predominantly IgG2 antibody response, the latter of which is associated with FcyRIV activation. Consistent with the isotype differences, adjuvanted gD-2 elicited higher neutralizing titers, whereas $\triangle \mathrm{gD}-2$ elicited significantly higher FcyR-activating responses (ADCC and $A D C P$ ). Although the neutralizing titer induced by gD-2 subunit vaccine was higher against SD90 compared to $\mathrm{B}^{3} \mathrm{x} 1.1$, the subunit vaccine provided greater protection against the latter in the murine studies. Greater protection against HSV-1 versus HSV-2 was also observed in a study with cotton rats, and in the Phase III field trial of the gD-2/AS04 vaccine (Boukhvalova et al. 2015; Stanberry et al. 2002; Awasthi, Belshe, et al. 2014; Burn et al. 2017). It is unclear whether the serotype differences in vaccine efficacy for the recombinant gD-2 vaccine (but not $\Delta g D-2$ ) reflect serotype differences in the immune response required to achieve protection. 
The notion that ADCC antibodies are important in preventing HSV disease is supported by clinical studies showing that low levels of transplacentally acquired ADCC antibodies at the time of infection correlated with the severity of neonatal disease even after controlling for neutralizing antibodies (Kohl 1991; Kohl et al. 1989). Indeed, vaccinologists have begun to challenge the reliance on neutralizing antibodies as the benchmark for vaccine efficacy for multiple pathogens. Indeed, a study with $\triangle \mathrm{gD}-2$ illustrated that maternal vaccination protected pups from HSV challenge (Kao et al. 2019). Ongoing studies in influenza, HIV, CMV and dengue have also demonstrated the importance of Fc effector functions such as ADCC and ADCP in immune protection (Laoprasopwattana et al. 2007; Corey et al. 2015; Nelson et al. 2018).

Several other attenuated HSV vaccines have been developed (Table 2) but are unlikely to advance as prophylactic vaccines because, unlike HSV529 and $\Delta \mathrm{gD}-2$, they cause variable levels of disease in mice and/or establish latency, rendering them less suitable for clinical development, particularly for prophylaxis. Nonetheless, the preclinical studies may provide additional insights into correlates of immune protection. For example, multiple studies have been conducted with viruses deleted in the gene for thymidine kinase (tk). Tk-deletion viruses are attenuated in adult but not neonatal mice (Ben-Hur et al. 1983; Oram et al. 2000) and cause significant disease in humans (Wilson et al. 2009). For example, Iwasaki and colleagues found that the "prime-pull" strategy, in which protective CD8 T cells were recruited into the vaginal tract in response to the intravaginal introduction of chemokines, was required for protection with a tk-deletion virus vaccine.(Shin and Iwasaki 2012)

Another attenuated strain that has been evaluated is HSV-2-gD27, a genetically modified HSV-2 strain in which the nectin-binding domain of $\mathrm{gD}$ is altered (Wang et al. 2012). Compared to wild-type virus, gD27 is less neurovirulent, but retains the ability to establish latency, albeit at reduced levels. Intramuscular immunization with this attenuated strain provided greater protection than a recombinant gD-2 subunit vaccine despite eliciting lower 
neutralizing antibody titers. These findings suggest that non-neutralizing immune responses contribute to the increased protection relative to recombinant $\mathrm{gD}$ subunit vaccines, although quantification of different antibody functions (e.g. ADCC or complement activation), T cell responses, passive transfer, or depletion studies have not yet been published (Wang et al. 2015).

An attenuated HSV-2 strain lacking the glycoprotein $\mathrm{K}(\mathrm{gK})$ gene provided partial protection against HSV-1 (strain McKrae) and HSV-2 (strain G) intravaginal challenge and elicited $\mathrm{T}$ cell memory immune responses to specific $\mathrm{gB}$ and $\mathrm{gD}$ epitopes that were detected 7 months post vaccination (lyer et al. 2013). However, the vaccine strain could establish latency, and, therefore, a second mutation in the membrane protein UL20 was introduced, resulting in the inability of the vaccine strain to establish latency in mice. This double $\mathrm{gK}$ and UL20 deletion strain (VC2) induced cross-protective neutralizing antibody responses in rhesus macaques as well as expansion of follicular $T$ helper $\left(T_{F H}\right)$ cells (Stanfield et al. 2017). In murine studies, VC2 provided $100 \%$ protection against HSV-1 (strain McKrae) and HSV-2 (strain G) intravaginal challenge and prevented the establishment of latency (Stanfield et al. 2014). In guinea pigs, the vaccine promoted a Th17 response to challenge, which was proposed to contribute to immune protection (Stanfield et al. 2018). Precisely why the double deletion prevented the establishment of latency and why it provided greater protection than the $\mathrm{gK}$ deletion virus is unclear.

In a related strategy designed to prevent the establishment of latency, an attenuated HSV-1 strain containing mutations in the UL37 tegument protein was found to be defective for retrograde axonal transport and unable to establish latent infections of the ganglia (Richards et al. 2017). In early preclinical studies, this vaccine (R2), administered intraocularly, protected mice from subsequent ocular challenge on the opposite side with HSV-1 strains F or McKrae. Pseudorabies virus (PRV) containing analogous mutations in the UL37 homolog provided protection from lethal challenge with wild-type PRV, suggesting that this strategy could be applied to both human and animal alphaherpesviruses (Richards et al. 2017). 
An HSV-2 virus containing a deletion in ICPO ( $\triangle$ NLS) has also been evaluated as a candidate vaccine (Halford et al. 2010). $\triangle N L S$ is replication-competent, but interferon-sensitive, which contributes to its attenuated phenotype in animal models. Because ICPO plays a major role in viral reactivation, the vaccine would likely be impaired in both the establishment and reactivation from latency, although this was not formally tested. $\triangle$ NLS provided greater protection against high-dose HSV-2 challenge compared to a gD-2 subunit vaccine in guinea pigs challenged intravaginally with HSV-2 (strain MS). It elicited polyantigenic immune responses including gD-2 specific and neutralizing antibodies, although the specific correlates of immune protection were not determined (Halford et al. 2011). The latter may be ascertained by performing passive transfer, antibody or $\mathrm{T}$ cell depletion and/or studies in defined knockout mice.

In a highly controversial step, Rational Vaccines circumvented the FDA and a safety Institutional Review Board (IRB) and tested ICPO $(\triangle N L S)$ in a Phase 1 safety study in $20 \mathrm{HSV}-1$ and/or HSV-2 seropositive volunteers with a history of genital herpes. Participants self-reported a reduction in symptoms. A Phase 2 study was planned but was disbanded when it became known that the vaccine had been tested without FDA or IRB input and without the requisite preclinical safety studies. Moreover, several participants reported adverse side effects.

\section{Therapeutic vaccines}

The vaccines candidates described above were developed primarily as prophylactic vaccines with the primary goal of preventing HSV-2 (or both HSV-1 and HSV-2) disease in seronegative hosts and/or preventing HSV-2 in HSV-1 seropositive hosts. Whether the types of immune responses needed for therapeutic vaccines, which are designed to reduce the frequency and severity of clinical recurrences and/or asymptomatic shedding, differ from those required for prophylaxis is not known. The "gold standard" model for evaluating therapeutic vaccines is the female guinea pig because the virus spontaneously 
reactivates. However, despite several vaccines demonstrating efficacy in this model, the clinical trial results have been disappointing.

For example, a vaccine composed of HSV-2 gD and ICP4 combined with a saponin adjuvant was evaluated in a Phase 2 study at three different doses (Van Wagoner et al. 2018). The vaccine boosted neutralizing antibody titers and increased the cytolytic $T$ cell response, but was associated with only a modest decrease in viral shedding (Genocea, Gen-003). Agenus Inc. developed a heat shock protein-based vaccine (HerpV) composed of a mixture of HSV-2 immunogenic peptides (including not only gD, but also other envelope, tegument, capsid, and regulatory viral proteins) and the saponinbased adjuvant QS-21. In a randomized, Phase 2, double-blind study, the majority of patients developed a robust anti-HSV cytotoxic T-cell immune response, but there was only a $17 \%$ reduction in frequency of viral shedding despite a 75\% reduction in viral load (Wald et al. 2011; Cohen 2017).

DNA may be more immunogenic than protein and, based on this notion, two other vaccines have been evaluated as candidate therapeutic vaccines. An HSV-2 DNA vaccine composed of gD and the tegument protein UL46 was advanced into the clinic after showing efficacy in the guinea pig recurrent disease model (Veselenak et al. 2012). However, the results were, once again, disappointing, and the vaccine failed to meet its clinical endpoint of annualized lesion recurrences during a minimum of nine months of surveillance. The Phase 2 study, in which volunteers were randomized 2:1 to vaccine or placebo, was conducted in 261 healthy HSV-2 seropositive adults with a self-reported history of 4 to 9 recurrences per year. Unfortunately, the annualized recurrence rate in the placebo group was lower than what was expected, and, thus, the trial did not have sufficient power to demonstrate efficacy (Vical 2018).

Another DNA-based vaccine based on a codon-optimized HSV-2 gD and the addition of a ubiquitin-encoding sequence to target the antigen to the proteasome for processing and to enhance cytotoxic $T$ cell responses, was evaluated in a Phase 2 therapeutic vaccine trial after demonstrating that it 
induced high-titer $\mathrm{gD}$-specific antibodies and $\mathrm{T}$ cell responses. The vaccine enhanced survival and a reduction in latent virus in a vaginal murine model (Dutton et al. 2013). However, while safe, the vaccine did not reduce the severity of clinical recurrences (Admedus 2018).

\section{Vector vaccine strategies}

An alternative to protein, DNA, or live attenuated or single-cycle vaccines is a vector vaccine strategy. Vector vaccines refer to the insertion of antigenic target genes from one pathogen into an unrelated vector "backbone". These have been evaluated, for example, as a strategy for HIV prevention (Draper and Heeney 2009). This approach has the potential to promote a T celldependent high-affinity class-switched response with memory, albeit to a more restricted set of antigens than a live virus virus. Depending on the vector backbone, this approach may be safer than a live vaccine, particularly in the case of HIV. However, the safety depends on the nature of the vector. The most commonly used vectors for HIV vaccines have been adeno-associated viruses, adenoviruses, and, more recently, a rhesus CMV vector (Barouch 2010; Hansen et al. 2011; Nieto and Salvetti 2014). These approaches may be limited by pre-existing immunity to the vector, which can decrease the efficacy. This was illustrated by the experience with a recombinant adenovirus serotype 5 (rAD5) HIV vaccine that may have enhanced HIV infection in the subpopulation of vaccinees with prior immunity to adenoviruses (STEP trial) (Buchbinder et al. 2008).

There have been several preclinical studies of vector vaccine strategies for the prevention or treatment of $\mathrm{HSV}$ that may provide insights for future development. For example, HSV-1 gB (gB-1) was introduced into a feline immunodeficiency virus (FIV) vector and tested against HSV-1 and HSV-2 vaginal challenges in mice. The vaccine elicited cross-neutralizing antibodies and cell-mediated responses that protected 100 and $75 \%$ animals from severe HSV-1- and HSV-2 disease, respectively, but not from infection (Chiuppesi et al. 2012). The authors proposed that the addition of other HSV viral genes into this vector might improve the immunogenicity and efficacy. 
In a different study, HSV gB and/or gD, lacking their transmembrane domains, were inserted into human papilloma virus pseudoviruses (HPV PsV) as a potential mucosal vaccine strategy, with the goal of eliciting protective genitalresident T cell responses (Çuburu et al. 2014). The PsV secrete the HSV viral glycoproteins. Investigators found that secreted $\mathrm{gB}$ (gBsec)-expressing HPV PsVs induced gB-peptide-specific $\mathrm{CD}^{+} \mathrm{T}$ cell responses. In subsequent studies, mucosal vaccination with PsVs expressing gBsec and gDsec were compared to intramuscular immunization with an adjuvanted (alum and MPL) recombinant gD-2 protein vaccine. Both provided a similar level of protection in mice following a lethal challenge (60\% and $80 \%$, respectively) (Çuburu et al. 2014). The PsV vaccine induced lower gD-specific and neutralizing antibody titers compared to recombinant gD-2 protein vaccine, but greater gB-specific CD8+ $T$ cell responses, highlighting a potential role for gB-specific $T$ cells.

A modified vaccinia Ankara (MVA) vaccine vector expressing HSV-2 gD (MVA$\mathrm{gD}$ ), used in combination with a gD-2-expressing plasmid vaccine, illustrated that the combination of the two delivery methods was effective in inducing robust anti-HSV IgG responses (Meseda et al. 2002; Meseda et al. 2006). The use of MVA-gD as either the prime and boost or as the prime followed by plasmid gD-2 as the boost induced a greater diversity of IgG isotype responses - shifting from an almost entirely lgG1 (predominantly neutralizing antibodies) to a combination of $\lg G 1$, IgG2a, and $\lg G 2 b$ responses (IgG2 antibodies have greater affinity for FcR and for complement). Both MVA-gD vector strategies resulted in greater survival following intraperitoneal challenge with HSV-2 as well as more IL-2 and IFN-y production following stimulation of splenocytes with inactivated HSV (Meseda et al. 2002).

Another study compared immunogenicity and efficacy of an MVA vector expressing the HSV capsid VP5 (UL19) and tegument VP13/14 (UL47) proteins to adjuvanted $\mathrm{gD}$ and $\mathrm{gC}$, and a combination of both the MVA vector and subunit proteins (Awasthi et al. 2015). The combination of MVA and subunit proteins elicited higher total and neutralizing antibody responses and 
greater protection compared to either component alone in mice or guinea pigs (Awasthi et al. 2015). There was also a greater reduction in the size of the latent reservoir in response the combination, compared to the $\mathrm{gD}$ and $\mathrm{gC}$ subunit vaccine, but no differences in viral shedding in the guinea pig model of recurrent disease. The results suggest that the MVA vector expressing viral antigens that are known to induce a $\mathrm{T}$ cell response provided a modest additional benefit compared to the subunit protein vaccine, although why this resulted in higher neutralizing titers is not known.

\section{Lessons learned and future directions}

The disappointing outcomes of clinical trials with HSV prophylactic and therapeutic vaccine candidates suggest several important lessons for future research. First, the established "gold-standard" preclinical small animal models (mice and guinea pigs) have not proven predictive of the human response. While the types of immune response (e.g. neutralizing antibody and/or $\mathrm{T}$ cell responses) observed in preclinical models were reproduced in humans, the magnitude of responses and the efficacy observed in mice or guinea pigs was not recapitulated. Studies conducted after the clinical trials were completed using higher dose challenges and a broader array of clinical isolates, provided a more predictive picture. For example, when mice were challenged with the clinical isolates HSV-2 (strain SD90) or HSV-1 (strain $\mathrm{B}^{3} \times 1.1$ ), only modest protection was observed in mice immunized with adjuvanted recombinant $\mathrm{gD}$ protein vaccines, more closely recapitulating the clinical trial results (Burn et al. 2017). Studies with a broad range of clinical isolates have not been reported in the guinea pig model of recurrent disease, which was also not predictive of clinical trial outcomes. For example, a gD-2 subunit vaccine underwent several rounds of adjuvant optimization, and the optimized product (gD-2/AS04) (Simplirix ${ }^{\mathrm{TM}}$ ) provided nearly complete protection against primary and recurrent disease with either HSV-1 or HSV-2 in guinea pigs (Bourne et al. 2003; Bourne et al. 2005; Bernstein et al. 2009; Bernstein et al. 2010) and was also effective in HSV-1 seropositive guinea pigs (Hoshino et al. 2009), results that were not replicated in the clinical trials. Thus, modifications of the guinea pig model, perhaps including clinical isolates, should be explored. 
Recent studies with a medroxyprogesterone (MPA)-treated cotton rat more closely recapitulated the outcomes of the Simplirix ${ }^{\mathrm{TM}}$ gD2 subunit vaccine. Cotton rats were primed and boosted intramuscularly with increasing doses of gD-2/AS04, a hepatitis B vaccine control (Fendrix), or PBS and subsequently challenged intravaginally with HSV-2(G) $\left(5 \times 10^{4} \mathrm{pfu}\right)$ or HSV-1(17) $\left(2 \times 10^{6}\right.$ pfu) (note that higher doses of HSV-1 were needed due to differences in virulence) (Boukhvalova et al. 2015). The gD/AS04 vaccine provided little or no protection at the lower doses $(0.06$ and $0.3 \mu \mathrm{g} / \mathrm{ml})$ and partial protection from disease (2/5 cotton rats had no lesions; $p=0.008$ compared to PBS, log rank test) when administered at the highest dose of $2 \mu \mathrm{g}$ per animal, which is $\sim 75$ fold higher than the human dose of $20 \mathrm{mg}$ of $\mathrm{gD}$. Moreover, there were no differences in amount of HSV-2 shed in vaginal washes in immunized cotton rats. However, the $2 \mu \mathrm{g}$ gD-2/AS04 dose completely protected cotton rats from HSV-1 disease and reduced viral shedding by $\sim 1.4 \log 10$ in animals vaccinated with $2 \mu \mathrm{g} g \mathrm{~g}-2 / \mathrm{AS} 04$. Consistent with clinical trial results, the gD-2/AS04 vaccine elicited $\mathrm{gD}$-specific neutralizing antibodies in the serum and passive transfer of serum from the immunized cotton rats to naïve cotton rats, protecting the latter from HSV-1 but not HSV-2 disease (Boukhvalova et al. 2015). These results suggest that the cotton rat could be a more predictive model, but further studies are needed. Notably, and distinct from guinea pigs, reagents for studying immune responses in cotton rats are readily available and continue to expand (Niewiesk 2009).

The second major lesson suggested by the HSV vaccine experience is the recognition that non-neutralizing antibody responses may play an important role in immune protection. This was first suggested by the failure of the Chiron $\mathrm{gD} / \mathrm{gB}$ subunit vaccine and is supported by limited clinical data showing that higher maternally-derived ADCC antibodies at the time of neonatal infection are associated with better clinical outcomes (Kohl 1991; Kohl et al. 1989). Preclinical studies comparing an adjuvanted gD-2 subunit vaccine, which elicits an almost exclusively neutralizing antibody response, to the $\Delta \mathrm{gD}-2$ single-cycle candidate vaccine, which elicits a predominantly ADCC response, further 
highlight the role of ADCC responses. The latter vaccine provided $100 \%$ protection against clinical isolates of either serotype in male and female mice and prevented the establishment of latency, whereas the former provided only partial protection against disease and no protection against latency (Burn et al. 2017). Moreover, the immune serum from $\Delta g D$-2-immunized, but not gD subunit-immunized mice, provided complete protection when passively transferred to naïve mice. In addition, $\Delta \mathrm{gD}-2$ but not the adjuvanted gD subunit vaccine, protected HSV-1 seropositive mice from subsequent challenge with HSV-2 and this protection correlated with ADCC and not neutralizing antibody responses (Burn Aschner, Knipe, et al. 2020).

Precisely what antigenic and host factors determine whether a neutralizing and/or non-neutralizing FcyR-activating antibody response will be elicited to vaccination or infection is complex and requires further study. However, the history of failed HSV vaccine trials, which focused predominantly on generating neutralizing gD-specific antibody responses, and the ability of HSV to escape neutralizing antibodies by spreading directly from cell-to-cell, suggest that optimal protection will require polyfunctional non-neutralizing immune responses. The importance of these more complex immune responses is supported by ongoing vaccine efforts with other viruses, including CMV, HIV, and influenza, and by the success with VZV vaccines, which are not restricted to the generation of neutralizing antibody responses. The expanding ability to genetically engineer viruses and construct DNA, RNA, and protein vaccines with new adjuvants, in combination with new tools to evaluate immune responses, portends future success in developing vaccine(s) for HSV prevention and treatment.

\section{Acknowledgements}

$\mathrm{BCH}$ is supported by NIH NIAID and NICHD, X-Vax Technology and the Price Family Foundation. CBA is supported by a Howard Hughes Medical Institute International Student Research Fellowship. 


\section{Disclosures}

Betsy C. Herold holds a patent for the $\Delta g D-2$ vaccine.

\section{References}

Abendroth, A. et al., 2000. Modulation of major histocompatibility class II protein expression by varicella-zoster virus. Journal of Virology, 74(4), pp. 1900-1907.

Abendroth, A. et al., 2001. Varicella-zoster virus retains major histocompatibility complex class I proteins in the Golgi compartment of infected cells. Journal of Virology, 75(10), pp.4878-4888.

Admedus, 2018. ADMEDUS HSV 2 PHASE IIA RESULTS - MAY 2017.

Ahn, K. et al., 1996. Molecular mechanism and species specificity of TAP inhibition by herpes simplex virus ICP47. The EMBO journal, 15(13), pp. 3247-3255.

Argaw, T. et al., 2000. Nucleotide sequences that distinguish Oka vaccine from parental Oka and other varicella-zoster virus isolates. Journal of Infectious Diseases, 181(3), pp.1153-1157.

Arvin, A. and Gershon, A., 2006. Control of Varicella. The Pediatric Infectious Disease Journal, 25(6), pp.475-476.

Arvin, A.M., 2008. Humoral and Cellular Immunity to Varicella-Zoster Virus: An Overview. Journal of Infectious Diseases, 197(s2), pp.S58-S60.

Asano, Y. and Takahashi, M., 1977. Clinical and serologic testing of a live varicella vaccine and two-year follow-up for immunity of the vaccinated children. PEDIATRICS, 60(6), pp.810-814.

Awasthi, S. et al., 2015. A Dual-Modality Herpes Simplex Virus 2 Vaccine for Preventing Genital Herpes by Using Glycoprotein C and D Subunit Antigens To Induce Potent Antibody Responses and Adenovirus Vectors Containing Capsid and Tegument Proteins as T Cell Immunogens L. Hutt-Fletcher, ed. Journal of Virology, 89(16), pp.8497-8509.

Awasthi, S. et al., 2019. Nucleoside-modified mRNA encoding HSV-2 glycoproteins C, D, and E prevents clinical and subclinical genital herpes. Science immunology, 4(39), p.eaaw7083. 
Awasthi, S., Belshe, R.B. and Friedman, H.M., 2014. Better Neutralization of Herpes Simplex Virus Type 1 (HSV-1) Than HSV-2 by Antibody From Recipients of GlaxoSmithKline HSV-2 Glycoprotein D2 Subunit Vaccine. Journal of Infectious Diseases, 210(4), pp.571-575.

Awasthi, S., Hook, L.M., Shaw, C.E. and Friedman, H.M., 2017. A trivalent subunit antigen glycoprotein vaccine as immunotherapy for genital herpes in the guinea pig genital infection model. Human Vaccines and Immunotherapeutics, 13(12), pp.2785-2793.

Awasthi, S., Hook, L.M., Shaw, C.E., Pahar, B., et al., 2017. An HSV-2 Trivalent Vaccine Is Immunogenic in Rhesus Macaques and Highly Efficacious in Guinea Pigs L. Hutt-Fletcher, ed. PLoS Pathogens, 13(1), pp.e1006141-24.

Awasthi, S., Huang, J., et al., 2014. Blocking Herpes Simplex Virus 2 Glycoprotein E Immune Evasion as an Approach To Enhance Efficacy of a Trivalent Subunit Antigen Vaccine for Genital Herpes. Journal of Virology, 88(15), pp.8421-8432.

Barouch, D.H., 2010. Novel adenovirus vector-based vaccines for HIV-1. Current Opinion in HIV and AIDS, 5(5), pp.386-390.

Bartha, A., 1961. Experimental reduction of virulence of Aujeszky's disease virus. Mag. Allatorv. Lapja, 16, pp.42-45.

Belshe, R.B. et al., 2012. Efficacy results of a trial of a herpes simplex vaccine. New England Journal of Medicine, 366(1), pp.34-43.

Ben-Hur, T. et al., 1983. Neurovirulence of herpes simplex virus type 1 depends on age in mice and thymidine kinase expression. Archives of virology, 78(3-4), pp.303-308.

Berkowitz, E.M. et al., 2014. Safety and Immunogenicity of an Adjuvanted Herpes Zoster Subunit Candidate Vaccine in HIV-Infected Adults: A Phase 1/2a Randomized, Placebo-Controlled Study. Journal of Infectious Diseases, 211(8), pp.1279-1287.

Bernard, M.-C. et al., 2015. Immunogenicity, Protective Efficacy, and NonReplicative Status of the HSV-2 Vaccine Candidate HSV529 in Mice and Guinea Pigs L. BenMohamed, ed. PLoS ONE, 10(4), pp.e0121518-21. 
Bernstein, D.I. et al., 2009. Potent adjuvant activity of cationic liposome-DNA complexes for genital herpes vaccines. Clinical and vaccine immunology : CVI, 16(5), pp.699-705.

Bernstein, D.I. et al., 2010. The adjuvant CLDC increases protection of a herpes simplex type 2 glycoprotein $D$ vaccine in guinea pigs. Vaccine, 28(21), pp.3748-3753.

Boukhvalova, M. et al., 2015. Efficacy of HSV-2 Glycoprotein D/AS04 vaccine against genital HSV-2 and HSV-1 infection and disease in the cotton rat Sigmodon hispidus model. Journal of Virology.

Bourne, N. et al., 2003. Herpes simplex virus (HSV) type 2 glycoprotein D subunit vaccines and protection against genital HSV-1 or HSV-2 disease in guinea pigs. Journal of Infectious Diseases, 187(4), pp.542-549.

Bourne, N. et al., 2005. Impact of immunization with glycoprotein D2/AS04 on herpes simplex virus type 2 shedding into the genital tract in guinea pigs that become infected. Journal of Infectious Diseases, 192(12), pp.2117-2123.

Boursnell, M.E. et al., 1997. A genetically inactivated herpes simplex virus type 2 (HSV-2) vaccine provides effective protection against primary and recurrent HSV-2 disease. Journal of Infectious Diseases, 175(1), pp.16-25.

Brunell, P.A. et al., 1982. Administration of live varicella vaccine to children wtih leukaemia. The Lancet, 2(8307), pp.1069-1073.

Buchbinder, S.P. et al., 2008. Efficacy assessment of a cell-mediated immunity HIV-1 vaccine (the Step Study): a double-blind, randomised, placebocontrolled, test-of-concept trial. Lancet (London, England), 372(9653), pp. 1881-1893.

Burn Aschner, C., Knipe, D.M. and Herold, B.C., 2020. Model of vaccine efficacy against HSV-2 superinfection of HSV-1 seropositive mice demonstrates protection by antibodies mediating cellular cytotoxicity. $n p j$ Vaccines, 5:35

Burn, C. et al., 2017. An HSV-2 single-cycle candidate vaccine deleted in glycoprotein $\mathrm{D}, \Delta \mathrm{gD}-2$, protects male mice from lethal skin challenge with clinical isolates of HSV-1 and HSV-2. Journal of Infectious Diseases, pp.1-5.

Carfi, A. et al., 2002. Crystallization and preliminary diffraction studies of the ectodomain of the envelope glycoprotein $D$ from herpes simplex virus 1 alone 
and in complex with the ectodomain of the human receptor HveA. Acta crystallographica. Section D, Biological crystallography, 58(Pt 5), pp.836-838.

Carfi, A. et al., 2001. Herpes simplex virus glycoprotein D bound to the human receptor HveA. Molecular cell, 8(1), pp.169-179.

Cheung, T.C. et al., 2009. Unconventional ligand activation of herpesvirus entry mediator signals cell survival. Proceedings of the National Academy of Sciences, 106(15), pp.6244-6249.

Chew, T., Taylor, K. and Mossman, K., 2009. Innate and Adaptive Immune Responses to Herpes Simplex Virus. Viruses, 1(3), pp.979-1002.

Chiuppesi, F. et al., 2012. A Lentiviral Vector-Based, Herpes Simplex Virus 1 (HSV-1) Glycoprotein B Vaccine Affords Cross-Protection against HSV-1 and HSV-2 Genital Infections. Journal of Virology, 86(12), pp.6563-6574.

Cohen, J.I., 2017. Vaccination to Reduce Reactivation of Herpes Simplex Virus 2. Journal of Infectious Diseases, pp.jix006-3.

Compaan, D.M. et al., 2005. Attenuating lymphocyte activity: the crystal structure of the BTLA-HVEM complex. The Journal of biological chemistry, 280(47), pp.39553-39561.

Connolly, S.A. et al., 2002. Structure-Based Analysis of the Herpes Simplex Virus Glycoprotein D Binding Site Present on Herpesvirus Entry Mediator HveA (HVEM). Journal of Virology, 76(21), pp.10894-10904.

Connolly, S.A. et al., 2003. Structure-based mutagenesis of herpes simplex virus glycoprotein $D$ defines three critical regions at the gD-HveA/HVEM binding interface. Journal of Virology, 77(14), pp.8127-8140.

Corey, L. et al., 2015. Immune correlates of vaccine protection against HIV-1 acquisition. Science Translational Medicine, 7(310), pp.310rv7-310rv7.

Corey, L. et al., 1999. Recombinant glycoprotein vaccine for the prevention of genital HSV-2 infection: two randomized controlled trials. Chiron HSV Vaccine Study Group. JAMA, 282(4), pp.331-340.

Cunningham, A.L. et al., 2016. Efficacy of the Herpes Zoster Subunit Vaccine in Adults 70 Years of Age or Older. New England Journal of Medicine, 375(11), pp.1019-1032.

Çuburu, N. et al., 2014. Topical Herpes Simplex Virus 2 (HSV-2) Vaccination with Human Papillomavirus Vectors Expressing gB/gD Ectodomains Induces 
Genital-Tissue-Resident Memory CD8 +T Cells and Reduces Genital Disease and Viral Shedding after HSV-2 Challenge R. M. Sandri-Goldin, ed. Journal of Virology, 89(1), pp.83-96.

Da Costa, X.J.E.A. et al., 2000. Construction, phenotypic analysis, and immunogenicity of a UL5/UL29 double deletion mutant of herpes simplex virus 2. Journal of Virology, 74(17), pp.7963-7971.

Da Costa, X.J.E.A., Morrison, L.A. and Knipe, D.M., 2001. Comparison of Different Forms of Herpes Simplex Replication-Defective Mutant Viruses as Vaccines in a Mouse Model of HSV-2 Genital Infection. Virology, 288(2), pp. 256-263.

de Bruyn, G. et al., 2006. A randomized controlled trial of a replication defective ( $\mathrm{gH}$ deletion) herpes simplex virus vaccine for the treatment of recurrent genital herpes among immunocompetent subjects. Vaccine, 24(7), pp. 914-920.

Draper, S.J. and Heeney, J.L., 2009. Viruses as vaccine vectors for infectious diseases and cancer. Nature Reviews Microbiology, 8(1), pp.62-73.

Dropulic, L. et al., 2017. A Replication-Defective Herpes Simplex Virus (HSV)-2 Vaccine, HSV529, is Safe and Well-Tolerated in Adults with or without HSV Infection and Induces Significant HSV-2 Specific Antibody Responses in HSV Seronegative Individuals. Open Forum Infectious Diseases, (4), pp.S415S416.

Dropulic, L.K. et al., 2019. A Randomized, Double-Blinded, Placebo-Controlled, Phase 1 Study of a Replication-Defective Herpes Simplex Virus (HSV) Type 2 Vaccine, HSV529, in Adults With or Without HSV Infection. Journal of Infectious Diseases, 220(6), pp.990-1000.

Dubin, G. et al., 1991. Herpes simplex virus type $1 \mathrm{Fc}$ receptor protects infected cells from antibody-dependent cellular cytotoxicity. Journal of Virology, 65(12), pp.7046-7050.

Dudek, T.E. et al., 2011. Evidence for Differences in Immunologic and Pathogenesis Properties of Herpes Simplex Virus 2 Strains From the United States and South Africa. Journal of Infectious Diseases, 203(10), pp. 1434-1441. 
Dutton, J.L. et al., 2013. A Novel DNA Vaccine Technology Conveying Protection against a Lethal Herpes Simplex Viral Challenge in Mice A. A. Ashkar, ed. PLoS ONE, 8(10), pp.e76407-10.

Faga, B. et al., 2001. Identification and Mapping of Single Nucleotide Polymorphisms in the Varicella-Zoster Virus Genome. Virology, 280(1), pp. 1-6.

Freuling, C.M., Müller, T.F. and Mettenleiter, T.C., 2017. Vaccines against pseudorabies virus (PrV). Veterinary Microbiology, 206, pp.3-9.

Friedman, H.M. et al., 1984. Glycoprotein C of herpes simplex virus 1 acts as a receptor for the $\mathrm{C} 3 \mathrm{~b}$ complement component on infected cells. Nature, 309(5969), pp.633-635.

Fries, L.F. et al., 1986. Glycoprotein C of herpes simplex virus 1 is an inhibitor of the complement cascade. The Journal of Immunology, 137(5), pp. 1636-1641.

Früh, K. et al., 1995. A viral inhibitor of peptide transporters for antigen presentation. Nature, 375(6530), pp.415-418.

Gerber, S.I., Belval, B.J. and Herold, B.C., 1995. Differences in the role of glycoprotein $\mathrm{C}$ of HSV-1 and HSV-2 in viral binding may contribute to serotype differences in cell tropism. Virology, 214(1), pp.29-39.

Gershon, A.A., 1980. Live attenuated Varicella-Zoster vaccine. Reviews of infectious diseases, 2(3), pp.393-407.

Gershon, A.A., LaRussa, P. and Steinberg, S., 1994. Detection of antibodies to varicella-zoster virus using a latex agglutination assay. Clinical and diagnostic virology, 2(4-5), pp.271-277.

Grauwet, K. et al., 2014. Modulation of CD112 by the alphaherpesvirus gD protein suppresses DNAM-1-dependent NK cell-mediated lysis of infected cells. Proceedings of the National Academy of Sciences, 111(45), pp. 16118-16123.

Guzzetta, G. et al., 2013. Hope-Simpson's Progressive Immunity Hypothesis as a Possible Explanation for Herpes Zoster Incidence Data. American Journal of Epidemiology, 177(10), pp.1134-1142. 
Halford, W.P. et al., 2011. A Live-Attenuated HSV-2 ICPO- Virus Elicits 10 to 100 Times Greater Protection against Genital Herpes than a Glycoprotein D Subunit Vaccine R. Mosley, ed. PLoS ONE, 6(3), pp.e17748-18.

Halford, W.P., Püschel, R. and Rakowski, B., 2010. Herpes Simplex Virus 2 ICPO- Mutant Viruses Are Avirulent and Immunogenic: Implications for a Genital Herpes Vaccine D. P. Martin, ed. PLoS ONE, 5(8), pp.e12251-17.

Hansen, S.G. et al., 2011. Profound early control of highly pathogenic SIV by an effector memory T-cell vaccine. Nature, 473(7348), pp.523-527.

Harrop, J.A., McDonnell, P.C., et al., 1998. Herpesvirus entry mediator ligand (HVEM-L), a novel ligand for HVEM/TR2, stimulates proliferation of T cells and inhibits HT29 cell growth. The Journal of biological chemistry, 273(42), pp.27548-27556.

Harrop, J.A., Reddy, M., et al., 1998. Antibodies to TR2 (herpesvirus entry mediator), a new member of the TNF receptor superfamily, block $\mathrm{T}$ cell proliferation, expression of activation markers, and production of cytokines. The Journal of Immunology, 161(4), pp.1786-1794.

Hattori, A. et al., 1976. Use of live varicella vaccine in children with acute leukaemia or other malignancies. The Lancet, 2(7978), p.210.

Hill, A. et al., 1995. Herpes simplex virus turns off the TAP to evade host immunity. Nature, 375(6530), pp.411-415.

Hope-Simpson, R.E., 1965. The nature of herpes zoster: a long-term study and a new hypothesis. Proceedings of the royal society of medicine, 58, pp.9-20.

Hoshino, Y. et al., 2004. Comparative Efficacy and Immunogenicity of Replication-Defective, Recombinant Glycoprotein, and DNA Vaccines for Herpes Simplex Virus 2 Infections in Mice and Guinea Pigs. Journal of Virology, 79(1), pp.410-418.

Hoshino, Y. et al., 2008. Comparison of immunogenicity and protective efficacy of genital herpes vaccine candidates herpes simplex virus 2 dl5-29 and dl5-29-41L in mice and guinea pigs. Vaccine, 26(32), pp.4034-4040.

Hoshino, Y. et al., 2009. Protection from herpes simplex virus (HSV)-2 infection with replication-defective HSV-2 or glycoprotein D2 vaccines in HSV-1seropositive and HSV-1-seronegative guinea pigs. Journal of Infectious Diseases, 200(7), pp.1088-1095. 
Ihara, T. et al., 1994. Cytotoxicity against varicella zoster virus infected targets in children with acute leukemia. Acta paediatrica Japonica : Overseas edition, 36(1), pp.53-56.

lyer, A.V. et al., 2013. Single dose of Glycoprotein K (gK)-deleted HSV-1 liveattenuated virus protects mice against lethal vaginal challenge with HSV-1 and HSV-2 and induces lasting T cell memory immune responses. Virology journal, 10(1), p.317.

James, S.H. and Kimberlin, D.W., 2015. Neonatal Herpes Simplex Virus Infection. Infectious disease clinics of North America, 29(3), pp.391-400.

Jones, J.O. and Arvin, A.M., 2006. Inhibition of the NF-kappaB pathway by varicella-zoster virus in vitro and in human epidermal cells in vivo. Journal of Virology, 80(11), pp.5113-5124.

Kamiya, H. et al., 1982. Antibody-dependent cell-mediated cytotoxicity against varicella-zoster virus-infected targets. Infection and Immunity, 38(2), pp. 554-557.

Kao, C.M. et al., 2019. Murine Model of Maternal Immunization Demonstrates Protective Role for Antibodies That Mediate Antibody-Dependent Cellular Cytotoxicity in Protecting Neonates From Herpes Simplex Virus Type 1 and Type 2. Journal of Infectious Diseases, 42, pp.47-10.

Kohl, S., 1991. Role of antibody-dependent cellular cytotoxicity in defense against herpes simplex virus infections. Reviews of infectious diseases, 13(1), pp.108-114.

Kohl, S. et al., 2000. Limited antibody-dependent cellular cytotoxicity antibody response induced by a herpes simplex virus type 2 subunit vaccine. Journal of Infectious Diseases, 181(1), pp.335-339.

Kohl, S. et al., 1989. Neonatal antibody-dependent cellular cytotoxic antibody levels are associated with the clinical presentation of neonatal herpes simplex virus infection. Journal of Infectious Diseases, 160(5), pp.770-776.

Krause, P.R. and Klinman, D.M., 2000. Varicella vaccination: evidence for frequent reactivation of the vaccine strain in healthy children. Nature medicine, 6(4), pp.451-454.

Kronenberg, A. et al., 2005. Retrospective analysis of varicella zoster virus $(V Z V)$ copy DNA numbers in plasma of immunocompetent patients with 
herpes zoster, of immunocompromised patients with disseminated VZV disease, and of asymptomatic solid organ transplant recipients. Transplant infectious disease : an official journal of the Transplantation Society, 7(3-4), pp.116-121.

Kwak, B.O. et al., 2017. Genotype analysis of ORF 62 identifies varicellazoster virus infections caused by a vaccine strain in children. Archives of virology, 162(6), pp.1725-1730.

Kwon, B.S. et al., 1997. A newly identified member of the tumor necrosis factor receptor superfamily with a wide tissue distribution and involvement in lymphocyte activation. The Journal of biological chemistry, 272(22), pp. $14272-14276$.

Lal, H. et al., 2015. Efficacy of an Adjuvanted Herpes Zoster Subunit Vaccine in Older Adults. New England Journal of Medicine, 372(22), pp.2087-2096.

Laoprasopwattana, K. et al., 2007. Antibody-Dependent Cellular Cytotoxicity Mediated by Plasma Obtained before Secondary Dengue Virus Infections: Potential Involvement in Early Control of Viral Replication. Journal of Infectious Diseases, 195(8), pp.1108-1116.

Ljungman, P. et al., 1986. Clinical and subclinical reactivations of varicellazoster virus in immunocompromised patients. Journal of Infectious Diseases, 153(5), pp.840-847.

Looker, K.J. et al., 2017. Effect of HSV-2 infection on subsequent HIV acquisition: an updated systematic review and meta-analysis. The Lancet Infectious ....

Looker, K.J. et al., 2015. Global Estimates of Prevalent and Incident Herpes Simplex Virus Type 2 Infections in 2012. PLoS ONE, 10(1), pp.e114989-23.

Mark, K.E. et al., 2008. Rapidly Cleared Episodes of Herpes Simplex Virus Reactivation in Immunocompetent Adults. Journal of Infectious Diseases, 198(8), pp.1141-1149.

Mauri, D.N. et al., 1998. LIGHT, a new member of the TNF superfamily, and lymphotoxin alpha are ligands for herpesvirus entry mediator. Immunity, 8(1), pp.21-30. 
McLean, C.S. et al., 1994. Protective vaccination against primary and recurrent disease caused by herpes simplex virus (HSV) type 2 using a genetically disabled HSV-1. Journal of Infectious Diseases, 170(5), pp.1100-1109.

McNearney, T.A., 1987. Herpes simplex virus glycoproteins gC-1 and gC-2 bind to the third component of complement and provide protection against complement- mediated neutralization of viral infectivity. Journal of Experimental Medicine, 166(5), pp.1525-1535.

Meseda, C.A. et al., 2002. Prime-boost immunization with DNA and modified vaccinia virus ankara vectors expressing herpes simplex virus-2 glycoprotein $D$ elicits greater specific antibody and cytokine responses than DNA vaccine alone. Journal of Infectious Diseases, 186(8), pp.1065-1073.

Meseda, C.A., Stout, R.R. and Weir, J.P., 2006. Evaluation of a needle-free delivery platform for prime-boost immunization with DNA and modified vaccinia virus ankara vectors expressing herpes simplex virus 2 glycoprotein D. Viral immunology, 19(2), pp.250-259.

Moffat, J.F. et al., 1998. Attenuation of the vaccine Oka strain of varicella-zoster virus and role of glycoprotein $\mathrm{C}$ in alphaherpesvirus virulence demonstrated in the SCID-hu mouse. Journal of Virology, 72(2), pp.965-974.

Murphy, T.L. and Murphy, K.M., 2010. Slow Down and Survive: Enigmatic Immunoregulation by BTLA and HVEM. Annual Review of Immunology, 28(1), pp.389-411.

Ndjamen, B. et al., 2014. The herpes virus Fc receptor gE-gl mediates antibody bipolar bridging to clear viral antigens from the cell surface. PLoS Pathogens, 10(3), p.e1003961.

Nelson, C.S., Herold, B.C. and Permar, S.R., 2018. A new era in cytomegalovirus vaccinology: considerations for rational design of nextgeneration vaccines to prevent congenital cytomegalovirus infection. npj Vaccines, pp.1-9.

Nieto, K. and Salvetti, A., 2014. AAV Vectors Vaccines Against Infectious Diseases. Frontiers in Immunology, 5, p.5.

Niewiesk, S., 2009. Current animal models: cotton rat animal model. Current topics in microbiology and immunology, 330, pp.89-110. 
Okazaki, W., Purchase, H.G. and Burmester, B.R., 1970. Protection against Marek's disease by vaccination with a herpesvirus of turkeys. Avian diseases, 14(2), pp.413-429.

Oram, R.J. et al., 2000. Characterization of an acyclovir-resistant herpes simplex virus type 2 strain isolated from a premature neonate. Journal of Infectious Diseases, 181(4), pp.1458-1461.

Oxman, M.N., Levin, M.J.Shingles Prevention Study Group, 2008. Vaccination against Herpes Zoster and Postherpetic Neuralgia. Journal of Infectious Diseases, 197(s2), pp.S228-S236.

Papaevangelou, V. et al., 2013. Subclinical VZV reactivation in immunocompetent children hospitalized in the ICU associated with prolonged fever duration. Clinical microbiology and infection : the official publication of the European Society of Clinical Microbiology and Infectious Diseases, 19(5), pp.E245-51.

Peters, G.A. et al., 2012. The Attenuated Genotype of Varicella-Zoster Virus Includes an ORF0 Transitional Stop Codon Mutation. Journal of Virology, 86(19), pp.10695-10703.

Petro, C. et al., 2015. Herpes simplex type 2 virus deleted in glycoprotein D protects against vaginal, skin and neural disease. eLife.

Petro, C.D. et al., 2016. HSV-2 $\Delta g$ D elicits FcyR-effector antibodies that protect against clinical isolates. JCI Insight, 1(12), pp.1-15.

Quinlivan, M. and Breuer, J., 2006. Molecular studies of Varicella zoster virus. Reviews in Medical Virology, 16(4), pp.225-250.

Quinlivan, M.L. et al., 2012. Novel Genetic Variation Identified at Fixed Loci in ORF62 of the Oka Varicella Vaccine and in a Case of Vaccine-Associated Herpes Zoster. Journal of Clinical Microbiology, 50(5), pp.1533-1538.

Ramsey, N.L.M. et al., 2020. A single-cycle glycoprotein D deletion viral vaccine candidate, $\Delta g D-2$, elicits polyfunctional antibodies that protect against ocular herpes simplex virus. Journal of Virology.

Reszka, N.J., Dudek, T. and Knipe, D.M., 2010. Construction and properties of a herpes simplex virus 2 dl5-29 vaccine candidate strain encoding an HSV-1 virion host shutoff protein. Vaccine, 28(15), pp.2754-2762. 
Richards, A.L. et al., 2017. The pUL37 tegument protein guides alphaherpesvirus retrograde axonal transport to promote neuroinvasion D. A. Leib, ed. PLoS Pathogens, 13(12), pp.e1006741-32.

Roberts, C.M., Pfister, J.R. and Spear, S.J., 2003. Increasing Proportion of Herpes Simplex Virus Type 1 as a Cause of Genital Herpes Infection in College Students. Sexually Transmitted Diseases, 30(10), pp.797-800.

Sarrias, M.R. et al., 2000. The three HveA receptor ligands, gD, LT-alpha and LIGHT bind to distinct sites on HveA. Molecular Immunology, 37(11), pp. 665-673.

Sattentau, Q., 2008. Avoiding the void: cell-to-cell spread of human viruses. Nature Reviews Microbiology, 6(11), pp.815-826.

Schat, K.A. and Baranowski, E., 2007. Animal vaccination and the evolution of viral pathogens. Revue scientifique et technique, 26(2), pp.327-338.

Schmidt-Chanasit, J. and Sauerbrei, A., 2011. Evolution and world-wide distribution of varicella-zoster virus clades. Infection, genetics and evolution : journal of molecular epidemiology and evolutionary genetics in infectious diseases, 11(1), pp.1-10.

Sei, J.J. et al., 2015. Effector and Central Memory Poly-Functional CD4+ and CD8+ T Cells are Boosted upon ZOSTAVAX® Vaccination. Frontiers in Immunology, 6(Suppl 1), pp.675-15.

Shapiro, E.D. et al., 2011. Effectiveness of 2 Doses of Varicella Vaccine in Children. Journal of Infectious Diseases, 203(3), pp.312-315.

Shi, G., 2002. Mouse T cells receive costimulatory signals from LIGHT, a TNF family member. Blood, 100(9), pp.3279-3286.

Shin, H. and Iwasaki, A., 2012. A vaccine strategy that protects against genital herpes by establishing local memory T cells. Nature, 491(7424), pp.463-467.

Spear, P.G., 2004. Herpes simplex virus: receptors and ligands for cell entry. Cellular Microbiology, 6(5), pp.401-410.

Stadtmauer, E.A. et al., 2014. A phase 1/2 study of an adjuvanted varicellazoster virus subunit vaccine in autologous hematopoietic cell transplant recipients. Blood, 124(19), pp.2921-2929.

Stanberry, L.R. et al., 2002. Glycoprotein-D-adjuvant vaccine to prevent genital herpes. New England Journal of Medicine, 347(21), pp.1652-1661. 
Stanfield, B.A. et al., 2014. A single intramuscular vaccination of mice with the HSV-1 VC2 virus with mutations in the glycoprotein $\mathrm{K}$ and the membrane protein UL20 confers full protection against lethal intravaginal challenge with virulent HSV-1 and HSV-2 strains. PLoS ONE, 9(10), p.e109890.

Stanfield, B.A. et al., 2018. Intramuscular vaccination of guinea pigs with the live-attenuated human herpes simplex vaccine VC2 stimulates a transcriptional profile of vaginal Th17 and regulatory Tr1 responses. Vaccine, 36(20), pp.2842-2849.

Stanfield, B.A. et al., 2017. Vaccination of rhesus macaques with the liveattenuated HSV-1 vaccine VC2 stimulates the proliferation of mucosal T cells and germinal center responses resulting in sustained production of highly neutralizing antibodies. Vaccine, 35(4), pp.536-543.

Stiles, K.M. et al., 2010. Herpes Simplex Virus Glycoprotein D Interferes with Binding of Herpesvirus Entry Mediator to Its Ligands through Downregulation and Direct Competition. Journal of Virology, 84(22), pp.11646-11660.

Šedý, J.R. et al., 2004. B and T lymphocyte attenuator regulates T cell activation through interaction with herpesvirus entry mediator. Nature immunology, 6(1), pp.90-98.

Takahashi, M. et al., 1974. Live vaccine used to prevent the spread of varicella in children in hospital. The Lancet, 2(7892), pp.1288-1290.

Tamada, K. et al., 2000. LIGHT, a TNF-Like Molecule, Costimulates T Cell Proliferation and Is Required for Dendritic Cell-Mediated Allogeneic T Cell Response. The Journal of Immunology, 164(8), pp.4105-4110.

Tomazin, R. et al., 1996. Stable binding of the herpes simplex virus ICP47 protein to the peptide binding site of TAP. The EMBO journal, 15(13), pp. 3256-3266.

Van Wagoner, N. et al., 2018. Effects of Different Doses of GEN-003, a Therapeutic Vaccine for Genital Herpes Simplex Virus-2, on Viral Shedding and Lesions: Results of a Randomized Placebo-Controlled Trial. Journal of Infectious Diseases, 375, pp.1906-10.

Veselenak, R.L. et al., 2012. A Vaxfectin®-adjuvanted HSV-2 plasmid DNA vaccine is effective for prophylactic and therapeutic use in the guinea pig model of genital herpes. Vaccine, 30(49), pp.7046-7051. 
Vical, 2018. Vical Reports Phase 2 Trial of HSV-2 Therapeutic Vaccine Did Not Meet Primary Endpoint.

Wald, A. et al., 2000. Reactivation of genital herpes simplex virus type 2 infection in asymptomatic seropositive persons. New England Journal of Medicine, 342(12), pp.844-850.

Wald, A. et al., 2011. Safety and immunogenicity of long HSV-2 peptides complexed with rhHsc70 in HSV-2 seropositive persons. Vaccine, 29(47), pp. 8520-8529.

Wald, A. et al., 1995. Virologic characteristics of subclinical and symptomatic genital herpes infections. New England Journal of Medicine, 333(12), pp. 770-775.

Wang, K. et al., 2015. A Herpes Simplex Virus 2 (HSV-2) gD Mutant Impaired for Neural Tropism Is Superior to an HSV-2 gD Subunit Vaccine To Protect Animals from Challenge with HSV-2 R. M. Longnecker, ed. Journal of Virology, 90(1), pp.562-574.

Wang, K. et al., 2012. A herpes simplex virus 2 glycoprotein D mutant generated by bacterial artificial chromosome mutagenesis is severely impaired for infecting neuronal cells and infects only Vero cells expressing exogenous HVEM. Journal of Virology, 86(23), pp.12891-12902.

Watson, B. et al., 1995. Safety and cellular and humoral immune responses of a booster dose of varicella vaccine 6 years after primary immunization. Journal of Infectious Diseases, 172(1), pp.217-219.

Weibel, R.E. et al., 1985. Live Oka/Merck varicella vaccine in healthy children. Further clinical and laboratory assessment. JAMA, 254(17), pp.2435-2439.

Weinberg, A., Kroehl, M.E., et al., 2018. Comparative Immune Responses to Licensed Herpes Zoster Vaccines. Journal of Infectious Diseases, 218(suppl_2), pp.S81-S87.

Weinberg, A., Popmihajlov, Z., et al., 2018. Persistence of Varicella-Zoster Virus Cell-Mediated Immunity After the Administration of a Second Dose of Live Herpes Zoster Vaccine. Journal of Infectious Diseases, 352, pp.2271-4. White, C.J., 1996. Clinical trials of varicella vaccine in healthy children. Infectious disease clinics of North America, 10(3), pp.595-608. 
White, C.J. et al., 1991. Varicella vaccine (VARIVAX) in healthy children and adolescents: results from clinical trials, 1987 to 1989. PEDIATRICS, 87(5), pp.604-610.

Whitley, R.J., 2006. Herpes simplex encephalitis: Adolescents and adults. Antiviral Research, 71(2-3), pp.141-148.

Wilson, S.S., Fakioglu, E. and Herold, B.C., 2009. Novel approaches in fighting herpes simplex virus infections. Expert Review of Anti-infective Therapy, 7(5), pp.559-568.

Winston, D.J. et al., 2018. Inactivated varicella zoster vaccine in autologous haemopoietic stem-cell transplant recipients: an international, multicentre, randomised, double-blind, placebo-controlled trial. Lancet (London, England), 391(10135), pp.2116-2127. 